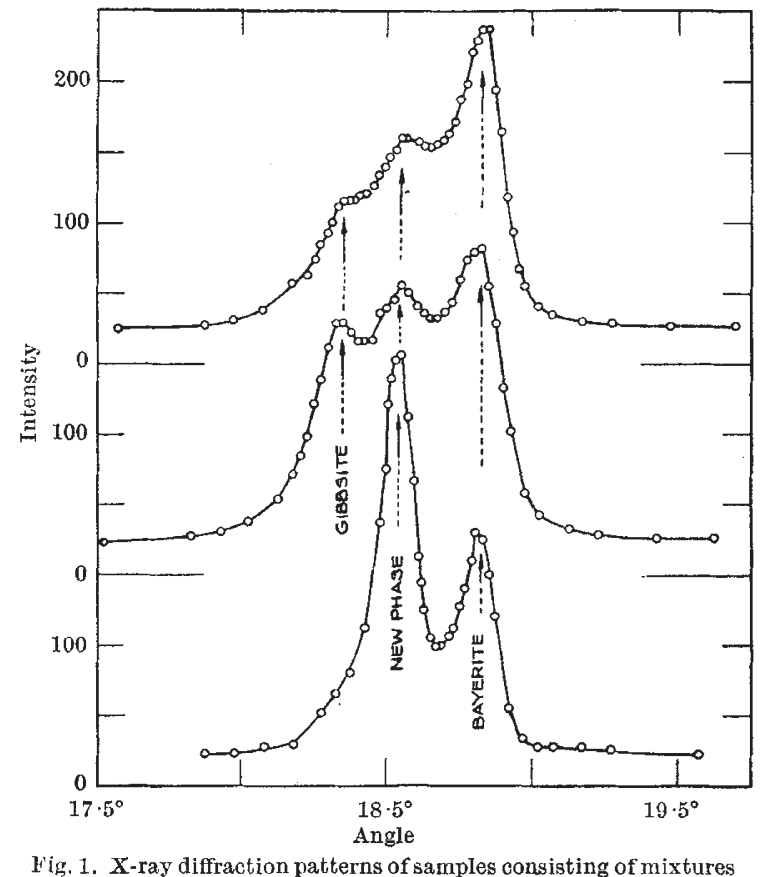

Fig. 1. X-ray diffraction patterns of samples consisting of mixture of the three alumina trihydrates

and the 4.720 bayerite lines are basal reflexions. The same may be assumed for the $4 \cdot 785 \mathrm{~A}$. line from the new phase, in view of its proximity and identical intensity. It would appear that the new phase with a 'layer spacing' equal to the average of the gibbsite and bayerite spacings may be a structure wherein the two types of packing alternate. This should lead to a weak X-ray reflexion corresponding to a two-layer periodicity for the new phase. No such reflexion has been observod. If present, its intensity is less than a thousandth of that of the $4 \cdot 785 \mathrm{~A}$. line.

The requirements cited by F. C. Frank ${ }^{3}$ and V. Vand ${ }^{4}$ for polymorphism arising from screw dislocations are fulfilled, namely, two closely related types of packing, the gibbsite and the bayerite types. There seems to be a good chance that the new phase is a screw dislocation polymorph, similar to the silicon carbide polymorphs. In the new phase the Burgers vector or height of the spiral growth step may be considered as two layers. The interface between these two layers would probably be a gibbsite-type interface. The interface between the stationary surface and the growing surface would be of bayerite type. Bayerite itself might then be looked upon as a screw dislocation growth form in which the Burgers vector was one layer-the constraint imposed during this type of growth may prevent the gibbsite-type packing, permitting instead a simple close-packing of the brucite type. Growth habits of these three phases seem to support this hypothesis. Electron microscopy and preferred orientation effects in X-ray diffraction indicate that gibbsite usually grows as platelets parallel to the layers of its layer lattice. Bayerite appears as rods or tapered rods the long direction of which appears roughly perpendicular to the layers of the layer lattice. The new phase appears intermediate, showing neither preferred orientation nor preferred growth directions.

The dehydration of all three trihydrates occurs at about $200^{\circ} \mathrm{C}$., gibbsite yielding $\chi$-alumina and boehmite; bayerite and the new phase yielding $\eta$-alumina. These distinctions are based upon the nomenclature of H. C. Stumpf et al. ${ }^{5}$.

Throughout our catalyst development programme the name 'randomite' was attached to this phase, as at first it was thought to be a random stacking structure. In view of the complete $\mathrm{X}$-ray pattern now available, it is clear that this nomenclature is inappropriate. We suggest that it be called bayeriteII, the original bayerite to be distinguished where necessary by Roman numeral as bayerite-I. Several reasons exist for suggesting a name showing its relationship to bayerite, including structure and growth features, conditions favouring formation, and dehydration products.

ROBERT A. VAN NORDSTRAND

WIIITAM P. HETTINGER

CARL D. K KrTH

Sinclair Research Laboratories, Inc., Harvey, Illinois.

$$
\text { Dec. } 5 .
$$

${ }^{1}$ Megaw, H., Z. Kryst., 87, 185 (1934).

${ }^{2}$ Unmack, A., abstracts of papers at Stockholm meeting of International Union of Crystallography, June 1951; also private communication.

${ }^{3}$ Frank, F. C., Phil. Mag., 42, 1014 (1951).

4 Vand, V., Nature, 168, 783 (1951). ${ }^{5}$ Stumpf, H. C., Russell, A. S., Newsome, J. W., and Tucker, C. M.,
Indust. Eng. Chem., 42, 1398 (1950).

\section{Self-inflation in a Gobioid Fish}

THE ability to inflate the body cavity by pumping in air or water through the mouth is found in several groups of fishes, chiefly highly specialized and otherwise rather degenerate types such as the well-known puffers, in certain forms from deeper waters and in some small sharks.

Mr. W. O. Mylo, of South-West Africa, recently sent me a small fish which was caught in a tide pool near Swakopmund, and which after capture blew itself up in the same fashion as a Tetraodon. On examination, this fish proved to be Gobius bibarbatus von Bonde, 1923. Although rather desiccated, it was plain that the abdomen had been considerably distended. On soaking, the fish became pliable and it was possible to estimate the degree of inflation that had been attained. In its distended condition the skin of the abdominal region bore scales, but each completely isolated in its own pocket. In the uninflated fish the abdomen is completely covered by normally imbricating scales. On distension these must slide apart leaving bare patches of translucent skin between. A skin structure of this type is unusual and would merit closer study in fresh material.

This is apparently the first case of a self-inflating mechanism to be reported in fishes of this type. Although generally placed in the broad genus Gobius Artedi, 1792, bibarbatus is distinguished from all other South African gobies by having what have generally been described as two 'barbels' beneath the chin. Examination reveals that these are not true barbels, but the briefly prolonged lateral apices of a low transverse mental skinny flap. This structure and the power of self-inflation clearly merit generic distinction for this fish, and Sufflogobius new genus is now proposed for it, genotypo bibarbatus von Bonde.

Rhodes University, J. L. B. SMItH Grahamstown,

South Africa. Jan. 9. 